\title{
ANALISIS PENGARUH PENINGKATAN BIAYA PEMBAYARAN TAGIHAN AIR BULANAN TERHADAP KEPUASAN KONSUMEN PADA PERUSAHAAN DAERAH AIR MINUM SAUMLAKI (PDAM)
}

\author{
Karel Gaus Basar, Nusnarera
}

Sekolah Tinggi Ilmu Ekonomi Saumlaki, karellusnarnera@gmail.com

\begin{abstract}
ABSTRAK
Penelitian ini bertujuan untuk menguji secara empiris pengaruh langsung atau tidak langsung dari 2 (dua) variabel yaitu : Peningkatan Biaya Pembayaran dan Kepuasan Konsumen, penelitian ini menggunakan data yang diperoleh dari Bank Perusahan Daerah Air Minum Saumlaki (PDAM) Kabupaten Maluku Tenggara Barat melalui Metode Purposive Sampling. Dari total kuisioner yang sebarkan sebanyak 101 kuisioner semuanya terisi dan dikembalikan, sampel yang di ambil adalah Konsumen Pengguna air bersi pada Perusahan Daerah Air Minum Saumlaki (PDAM) Kabupaten Maluku Tenggara Barat di Kota Saumlaki.

Metode analisis yang yang digunakan adalah Uji Validitas dan Uji Reliabilitas, serta Pengujian Hipotesis yang dilakukan dengan menggunakan analisis Regresi Sederhana. Hasil penelitian menunjukan bahwa Peningkatan Biaya Pembayaran berpengaruh sangat signifikan positif terhadap kepuasan konsumen.
\end{abstract}

Kata kunci : Peningkatan Biaya Pembayaran, Kepuasan Konsumen

\section{Pendahuluan}

Air merupakan kebutuhan utama (pokok) bagi semua makluk hidup di dunia ini,tanpa terkecuali manusia. Dengan demikian,dapat dikatakan bahwa manusia sangat membutukan air untuk memenuhi kebutuannya (keperluan ruma tangga, pertanian,perdagangan dan lain-lain) sehingga keberlagsungan hidup manusia bisa berjalan dengan baik. Melalui hal tersebut, maka air harus di kelolah dengan baik sehingga pemenfaatannya juga dapat lebih efektif dan efesien.

Air adalah sumber daya nasional yang menyangkut hajat hidup orang banyak,maka pengelolahannya di atur dan di pegang oleh pemerintah. Hal ini sesuai dengan UUD 1945 pasal 33 ayat (3) yang 
berbunyi : "bumi dan air dan kekayaan alam yang terkandung di dalamnya di kuasai oleh negara dan di pergunakan untuk sebesar-besarnya kemakmuran rakyat". Terkait dengan hal itu, pemerintah daerah juga telah mengeluarkan peraturan tentang pengelolahan sumber regional,yakni pasal 10 UU No 22 tahun 1999 tentang pemerintahan daerah yang menyatakan bahwa, 'Daerah berwewenang untuk mengolah sumber regional yang tersedia di wilayahnya dan bertanggung jawab memelihara kelestarian lingkungan sesuai dengan peraturan perundang-undangan'”Nugraha (2012). Sebagian bentuk penyerahan sebagai urusan

pemerintah dibidang pekerjaan umum kepada daerah, maka peraturan daerah pelaksanaannya diserahkan kepada seluruh instansi. Dalam hal ini adalah : Perusahan Daerah Air Minum Daerah ( PDAM ) Saumlaki, yang juga merupakan Badan Usaha Milik Daerah.

PDAM Saumlaki merupakan perusahan yang bergerak di bidang jasa penyediaan air bersih, yang sesuai dengan tujuannya dalam penyediaan, pengembangan pelayanan sarana dan prasarana serta distribusi air bersih, tak jau berbeda dengan kebutuan air pada umumnya bagi semua masyarakat, di MTB juga mengalami fenomena yang sama pada namun, ada beberapa hal yang membedakan di antaranya, di saat air mengalir tidak sesuai dengan yang di tentukan oleh PDAM, sehingga banyak komplen yang terjadi di masyarakat terkait dengan rutinitas air. Karenadengan rutinitas air mengalir yang tidak sesuai dengan kebutuan dari PDAM, sehingga membuat konsumen merasa kurang puas dengan hal tersebut. Selain itu, masalah air yang menjadi keluhan konsumen kepada pihak PDAM, terkait dengan rutinitas air yang mengalir tidak stabil 2-3 haripun maka konsumen merasa tidak puas saat melakukan pembayaran tagian air bulanan. Keadaan mengakibatkan,konsumen tidak merasa puas dalam pelayanan yang di berikan oleh PDAM, sehingga untuk memenuhi kebutuhan akan air bersih setiap hari, konsumen memili untuk membeli air dari tempat lain agar bisa memenuhi kebutuan akan air bersih. Kenyataan tersebut, mengakibatkan konsumen cenderung akan berpikir bahwa mereka telah dirugikan oleh pihak PDAM Saumlaki. Dalam proses pembelian air dari tempat lainpun tidak mudah untuk 
mendapatkannya, karena bukan cuma satu dari masyarakat yang membutukan air tersebut, melainkan seluruh masyarakat. Maka untuk mendapatkan air bersih dari tempat lain, masyarakat relah untuk menunggu bahkan sampai berjam-jam lamanya untuk mendapatkan air tersebut, karena mengingat banyaknya warga yang membutukannya.

Dalam situasi sperti ini, kepuasan konsumen sangat pentig untuk di perhatikan oleh pihak PDAM Saumlaki, karena jika pelayanan yang di berikan tidak sesuai dengan penigkatan biaya pemabayaran tagian air perbulan, maka parakonsumen akan melakukan suatu keluhan kepada pihak tersebut agar

\section{Tinjauan Pustaka}

Lukman (2013:4) biaya dalam arti luas pengorbanan sumber ekonomis yang di ukur dalam suatu mata uang yang telah terjadi atau kemugkinan terjadi dalam mencapai tujuan tertentu. Dalam arti sempit biaya adalah bagian harga pokok yang di korbankan dalam usaha memperoleh pengasilan. Menurut Masilys Kolmin dan Yunigsi (2009: 16 ) biaya adalah merupakan pengorbanan sumberdaya ekonomi perusahaan yang di pelayanan yang di berikan bukan hanya untuk memeras masyarakat melainkan memberikan pelayanan yang berkualitas secara terus menerus dan berkelanjutan, sekaligus bisa menigkatkan kepuasan konsumen secara nyata, tepat, dan terarah.

Dalam hal tersebut, PDAM Saumlaki harus mampuh untuk membuat strategi yang lebih baik dalam melayani masyrakat di kabupaten MTB, guna untuk memuskan masyarakat dalam pelayana akan air bersih, karena dari kenyataan yang di alami oleh masyarakat di saumlaki degan ketidak puasan mereka dalam melakukan pembayaran biaya tagian air setiap bulan di kantor PDAM saumlaki.

gunakan untuk memperoleh barang atau jasa. Biaya dapat di artikan sebagai pengorbanan,sumber ekonomi untuk memperoleh aktiva yang di sebut dengan istila harga pokok. Istila ini sering digunakan untuk menunjukan pengorbanan sumber ekonomi dalam begelolahan bahan baku.

Menurut Bastian dan Nurlela (2007:4) biaya atau Icost adalah pengorbanan sumber ekonomis di ukur dalam suatu uang yang telah terjadi atau kemugkinana akan terjadi untuk mencapai tujuan 
tertentu. Amin (1993:7) biaya adalah pengorbanan yang di lakukan untuk mendapatkan barang atau jasa .

Kepuasan bersal dari bahasa latin "satis”, yang berarti cukup dan sesuatu yang mumemuaskan akan secara pasti memenuhi harapan, kebutuhan, atau keinginan, dan tidak menibulkan keluhan Crow et.Al( 2003 : 28 ). Kepuasan menurut kamus bahasa Indonesia berasal dari kata puas yang di defenisikan sebagai suatu perasahan yang menyenangkan, karena terpenuhinya hasrat dan hati kepuasan itu sendiri di defenisikan sebagai prihal yang bersifat puas atau kesenagan jiwa karena terlah berkecukupan.

\section{Lebih}

lanjutOliver(2006:16)

mendefenisikan kepuasan sebagai tingkat perasahan seseorang setelah membandingkan hasil yang di rasakan dengan harapannya. Pakar lain mengatakan bahwa kepuasan merupakan respon sikap indifidu terhadap penilaian yang di dasarkan pada kongkrit dan di pengaruhi faktor emosi Crow et al (2003 : 28). Dengan demikian dapat di katakan bahwa kepuasan merupakan respon sikap indifidu yang bersifat subjetif terhadap obyek tertentu setelah membandingkannya bantara harapan dan kenyataan. Sikap indifidu terhadap suatu obyek menurut Berkowiz (2006:17), adalah perasahan mendukung atau memihak (favorable) maupun perasaan tidak mendukung atau tidak memihak ( unfavorable) pada obyek tersebut.

Menurut Kolter dan Keler yang di gterjemakan koleh Molan (2007; 177) yang di maksut dengan kepuasan adalah : "Perasaan kecewa atau senang seseorang yang muncul setelah membandingkan kinerja (hasil) prodak yang di pikirkan terhadap kinerja (hasil) yang di harapkan".

menghasilkan sesuatu yang nyaman secara rohani,bukan hanya nyaman karena di bayangkan atau di harapkan. Puas atau tidak puas bukanlah merupakan emosi melainkan sesuatu hasil evaluasi dari emosi

\section{Metode penelitian}

Penelitian manajemen pemasaran. Penelitian ini menganalisis hubugan pengaruh penigkatan biaya pembayaran terhadap kepuasan konsumen berdasarkan tingkat penjelasan yang ingin di hasilkan untuk menjawab permasalahan, maka jenis penelitian ini tergolong penelitin deskriptif yaitu, penelitian yang bertunjuan untuk membuat deskripsi, gambaran atau 
lukisan secara sistematis sesiau dengan fakta, sifat, serta hubungan antara fenomena yang di selediki. Penelitian dengan metode deskriptif juga di maksutkan untuk menjawab esensi dari obyek penelitiaan ini. Sedankan manfaat penggunaan penelitian deskriptif, selain untuk mengenali distrbusi dan perilaku data yang di miliki juga sebagai deasar pengambilan keputusan.

\section{Defenisi Operasiaonal Dan Pengukuran}

\section{Variabel}

Dari masing-masing konsep, maka penulis mengemukakan defenisi yang di gunakan dalam penuliasan ini adalah sebagaiberikut

1. Variabel Bebas (X) Biaya

Biaya adalah : suatu pengorbana sumber daya ekonomi yang di gunakan untuk memperoleh barang atau jasa.

Dari pengertian di atas, maka menurut Amin (1993: 7 ) biaya terdiri dari beberapa indicator sebagai berikut :
a. Kualitas barang
b. Harga yang di jangkau

2. Variabel Terikat (Y) Kepuasaan KonsumenKepuasan Konsumen adalah : perasaan senag atau kecewa yang berasal dari diri konsumen masing-masing terkait dengan apa hasil pelayana atau prodak yang di gunakan.

Dari penegrtian di atas maka menurut Thjitono (2007: 24) kepuasan konsumen terdiri dari ndikator sebagai berikut :
a. Ketetapan waktu
b. Kesesuai harapan
c. Pelayanan pegawai atau staf

\section{Teknik Analisis Data}

Analisis yang digunakan dalam penelitian ini yaitu menggunakan teknik analisis data Kuantitatif secara sederhana sering dikatakan sebagai penelitian ini dilakukan dengan mengumpulkan data berupa angka. Data yang berupa angka tersebut kemudian diolah dan danalisis untuk mendapatkan informasi ilmiah dibalik angka-angka tersebut ((Martono, 2010:19).

$$
\mathrm{Y}=\mathrm{a}+\mathrm{bx}
$$

Dimana :
Y :kepuasan konsumen
a : konstanta
$\mathrm{b}$ : kofisien regresi
$\mathrm{x}$ : biaya pembayaran

\section{Hasil dan Pembahasan}

\section{Sejarah singkat}


Perusahan Daerah Air Minum Kabupaten

Maluku Tenggara Barat, merupakan Badan Usaha Milik Daerah yang bergerak dibidang pelayanan air bersih, meliputi Kota Saumlaki dan Kecamatan Tanimbar Utara (larat).

Perusaan daerah ini beroprasi sejak 19 januari 2002 seiring dengan serah terima asset dari PDAM Maluku Tenggara ke Pemerintaan Kabupaten Maluku Ternggara Barat, dengan asset-aset yang ada pada Ibu Kota Kecamatan (IKK) saumlaki, larat, tepa dan wonleri.

Dasar Hukum Pendiri PDAM Kabupaten Maluku Tenggara Barat baru diperoleh pada bulan juli 2010 dengan peraturan Bupati Maluku Tenggara Barat Nomor 20 tahun 2010 tentang pembentukan Perusahan Daerah Air Minum Kabupaten Maluku Tenggara Barat.

Tugas Pokok PDAM Kabupaten MTB adalah menyelenggarakan pengelolahan air minum untuk meningkatkan kesejahtraan masyarakat yang mencakup aspek sosial, kesehatan dan pelayanan umum. Untuk melaksanakan tugas pokok tersebut PDAM
Kabupaten MTB mempunyai fungsi sebagai berikut

1. Melaksanakan pelayanan umum/jasa kepada masyarakat konsumen dalam penyediaan air bersih

2. Menyelenggarakan pemanfaatan umum yang dapat dirasakan oleh masyarakat.

3. Memupuk pendapatan umum pembiayaan kelangsungan hidup perusahan dan pengembangan daerah.

Pengumpulan data dalam penelitian ini dilakukan dengan menggunakan metode distribusi langsung (direct distribution method), yaitu dengan cara mendatangi secara langsung objek penelitian untuk menyerahkan kuisioner dan mengumpulnya kembali setelah selang waktu yang telah ditentukan. Responden dalam penelitian ini yaitu para Konsumen PDAM di Kota Saumlaki Kabupaten Maluku Tenggara Barat.

Tabel 4.1 Sampel dan Tingkat Pembagian

\begin{tabular}{|c|c|c|c|}
\hline $\begin{array}{c}\text { N } \\
\text { o }\end{array}$ & $\begin{array}{c}\text { Keterang } \\
\text { an }\end{array}$ & $\begin{array}{c}\text { Juml } \\
\text { ah }\end{array}$ & $\begin{array}{c}\text { Persenta } \\
\text { se }\end{array}$ \\
\hline & Kuisione & 101 & $100 \%$ \\
\cline { 4 - 5 } & & & \\
\cline { 3 - 4 } & & &
\end{tabular}




\begin{tabular}{|c|r|r|}
\hline Jumlah & 101 & $100 \%$ \\
\hline
\end{tabular}

Pendistribusian dan pengumpulan

kuisioner berlangsung selama 3 Minggu terhitung mulai tanggal 1Agustus sampai 20 Agustus 2017.

Jumlah kuisioner yang di distribusikan berjumlah 101 eksemplar. Kuisioner yang kembali berjumlah 101 eksemplar. Dari 101 eksemplar yang layak dianalisis dalam tabulasi data berjumlah 101 eksemplar. Jumlah sampel dan tingkat pengembaliannya dapat dilihat pada table 4

Tabel 4.2 Jumlah Sampel dan Tingkat Pengembalian

\begin{tabular}{|l|c|c|}
\hline $\begin{array}{l}\text { Kuisioner } \\
\text { yang } \\
\text { didistribusikan }\end{array}$ & $\begin{array}{c}101 \\
\text { eksemplar }\end{array}$ & $100 \%$ \\
\hline $\begin{array}{l}\text { Kuisioner } \\
\text { yang kembali }\end{array}$ & $\begin{array}{c}101 \\
\text { eksemplar }\end{array}$ & $100 \%$ \\
\hline
\end{tabular}

Berdasarkan Hasil pengujian hipotesis menunjukan pengaruh Biaya Pembayaranber pengaruh signifikan terhadap Kepuasan Konsumen. Dengan demikian, Biaya pembayaran dalam mencapai Kepuasan konsumen sangat ditentukan oleh Kualitas barang, , harga Yang di jangkau, , ketepatan waktu, kesesuaian, Pelayanan Pegawai. Hasil Vicki Taufik Nugraha( (2016) yang berjudul "Pengaruh Kualitas Pelayanan terhadap kepuasan konsumen pada PDAM Kota Bandung", mengemukakan bahwa Kualitas Pelayanan mempengaruhi Kepuasan Konsumen dimana pengaruh Kualitas Pelayanan terhadap kepuasan konsumen adalah positif. Dengan demikian hasil penelitian dari peneliti tersebut juga mendukung hasil penelitian yang saya lakukan tentang Pengaruh Biaya Pembayaran Terhadap Kepuasan Konsumen berpengaruh secara signifikan namun secara koefisien determinasi ternyata rendah karena variabel ini hanya $16,2 \%$ yang di pengaruhi oleh variabel ini.

\section{Kesimpulan}

Setelah melakukan analisis dan pengujian hipoteis Pengaruh Biaya Pembayaran terhadap konsumenn, Berdasarkan hasil olahan data diatas menunjukan bahwa Indikator Variabel Biaya : Kualitas Barabang, harag di jangkau berpengaruh terhadap Kepuasan konsumen : Keseusian harapan, Pelayanan Pegawai, Ketetapan waktu,. Dengan demikian dapat di simpulkan bahwa hipotesis pada penelitian ini menunjukan adanya pengaruh tingkat Biaya Pembayaran terhadap kepuasan konsumen pada PDAM di Saumlaki Kecamatan Tanimbar Selatan Kabupaten Maluku Tenggara Barat terbukti dengan 
pemberlakuannya. Artinya bahwa data yang dibutuhkan sesuai dengan hipotesis yang diajukan.

Dalam uji secara Parsial dapat diketahui bahwa : Kepuasan konsumen dengan $\mathrm{t}$ hitung $>\mathrm{t}$ tabel' yaitu $(4.502 \geq 2.581)$ hal ini dapat disimpulkan bahwa variabel Biaya pembayaran berpengaruh signifikan terhadap Kepuasan konsumen.

\section{DAFTAR PUSTAKA}

Alma Buchari. 2007. Manajemen Pemasaran dan Pemasaran Jasa, Edisi Revisi. Alfebeta. Bandung

Amin 1993. Manajemen produksi dan operasi . Edisi 4, LPEF, UI. Jokjakarta

Abdula 2016 :analissi pengarug biaya produksi berdasarkan metode full cousting dalam menentukan harga jual produk lemari

Crow Al 2013. Manajemen Pemasaran . Nurcahaya. Yogyakarta

Dharma Putra 2011 :analisis kepuasan pelaggan perusahan daerah air minum jembran

Dr. Riduwan, M.B.A.,M.P.D.Metode dan Teknik Menyusun Tesis, Penerbit Alfabeta, cetakan kesembilan februari 2003.

Jadfar. 2005. Manajemen Jasa . Ciawi Bogor

Fandi Tjiptono, Strategi Pemasaran, edisi ketiga, Andi Offset. Yogyakarta, 2007

Ghozali Imam 2006, Aplikasi Multivaliate dengan Program SPSS. Badan Penerbit UNDIP.
ImamGhozali. 2001. Aplikasi Analisis Multivariate dengan Program SPSS. Semarang : Badan Penerbit Universitas Diponegoro.

Kotler dan Keler.2007. Manajemen pemasaran Jilit 1. Ahli Bahasa oleh Benyamin Molan Edisi 12 .PT Indeks. Jakarta

Lukman. S. 2013 :Akuntansi Manajemen . PT Indeks. Jakarta

Nugraha. 2012, Pengaruh Kualitas Pelayanan Terhadapan kepuasan konsumen di PDAM Bandung

Nurlela 2016 Akutansi Biaya. Jilid 1. Graha Ilmu. Jakarta

Nurlela. 2007. Akuntansi Biaya Teori dan Aplikasi. Graha Ilmu. Yogyakarta

Olifer 2006. Manajemen Perbank

Supriyono 2000. Perencanaan dan pengendalian biaya serta pembuatan keputusan. BPFE. Yokyakarta

Sugiyono, 2005, Statistik Untuk Penelitian, CV. Alfabeta: Bandung.Nugraha 2012. :pengaruh kualitas pelayanan terhadap kepuasan konsumen di PDAM Bandung

Tijptono 2007 .Manajemen Jasa. Edisi kedua, Yokyakarta

Umar 2002. Riset Pemasaran dan Perilaku Konsumen Usein . Jakarta

Wijono 2000. Manajemen mutu pelayanan. Airlangga. Universitas Surabaya 
MIPA Fakultas MIPA, Universitas Negeri Yogyakarta.

Zakaria dan Rizki Yati. Analisa Sosiologi tentang Anak Putus Sekolah di Desa Merah Mege Kecamatan Atu Lintang Kabupaten Aceh Tengah. Universitas Syiah Kuala. 5 